\title{
Image Analysis of Blush Coverage Extent and Measures of Categorical Blush Intensity in 'Honeycrisp' Apples
}

\author{
H.E. Winzeler ${ }^{1}$ and J.R. Schupp \\ Department of Horticulture, Pennsylvania State University, Fruit Research \\ and Extension Center, 290 University Drive, Biglerville, PA 17307-9585
}

Additional index words. Malus $\times$ domestica, colorimetry, fruit color, spectrophotometry, photography, fruit appearance, fruit quality, consumer preference

\begin{abstract}
The coverage extent and intensity of apple blush are important factors in the evaluation of apple fruit quality for some cultivars. We analyzed blush coverage extent and intensity in the cultivar Honeycrisp to 1) define categories of marketable blush in terms relating to device-independent color measurements; 2) assess relationships among a modified anthocyanin index $\left(\mathrm{AI}_{\mathrm{m}}\right)$ calculated from spectral measurements, colorimetry (CO), and human judgment of apple blush intensity; 3) assess the efficacy of digital image analysis (DIA) of color-calibrated digital photography as a tool to measure blush coverage extent; and 4) explore differences between human judgment of blush coverage extent and DIA. $\mathrm{AI}_{\mathrm{m}}$ and $\mathrm{CO}$ were both effective in providing statistical categorical separation among five classes of apple blush in 'Honeycrisp': "non-blush," "slight non-marketable blush," "minimum quality marketable blush," "clear marketable blush," and "outstanding blush" as judged by human participants. The boundary between blush and non-blush was judged to be a hue angle less than $49.0 \pm 3.1 h_{a b}$ in CIELAB $L * C_{a b}{ }^{*} h_{a b}$ color space and an $\mathrm{AI}_{\mathrm{m}}$ value greater than $4.3 \pm 1.3$ at $\alpha<0.05$. DIA was less sensitive and did not show statistically significant differences between "clear marketable blush" and "outstanding marketable blush," although its use to distinguish the other categories was successful. All methods of analysis resulted in high agreement with respect to the blush/non-blush boundary (Cohen's kappa $\geq \mathbf{0 . 8 9 7}$ ).
\end{abstract}

The extent of apple peel covered by attractive red blush is a consideration in the evaluation of fruit quality of some apple cultivars. The U.S. Department of Agriculture has published grading standards for well-established apple cultivars that include percentage of blush coverage as a critical factor for determining whether apples of 12 different cultivars fall within the "Extra Fancy," "Fancy," or "U.S. No. 1" grades (USDA, 2002a). In addition to facilitating the grading of apples, apple color evaluation helps consumers make judgments about fruit ripeness, anticipation of sweet flavor, and visual appeal (Cliff et al., 2002; Saure, 1990). The extent and intensity of apple blush also helps researchers quantify the effects on visual appearance of treatments such as shading, pruning and other horticultural practices, chemical treatments, or genetic traits.

'Honeycrisp' is a popular apple cultivar that is experiencing intense market demand coupled with lack of market saturation (Karst, 2010). Although 'Honeycrisp' usually displays

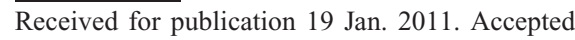
for publication 4 Mar. 2011.

We thank Melanie Schupp, Evan Moore, Tara Auxt Baugher, Thomas Kon, Katie Ellis, Tory Schmidt, Terry Salada, Joanne Myers, Rob Crassweller, and Dennis Decoteau for their technical contributions and/or manuscript editing.

${ }^{1}$ To whom reprint requests should be addressed; e-mail hew6@psu.edu.
}

attractive partial blush, blush coverage is generally not considered to be essential in the market success of 'Honeycrisp'. As market saturation for 'Honeycrisp' increases, however, consumer discernment may take the form of greater awareness of apple appearance, including blush intensity and blush coverage extent. With more 'Honeycrisp' apples to choose from in the future, consumers will likely become more active judges of the external appearance of 'Honeycrisp'.

The determination of apple blush coverage has conventionally been conducted by trained viewers who rely on visual inspection and expert judgment to compare candidate apples with reference color visual aids defining blush for particular apple grades (USDA, 2002b). Such visual inspections may be subject to variation as a result of inspector inconsistencies, differences of interpretation, personal preferences, inspector fatigue, and lack of precision in blush standard definitions. Objective measures of apple blush coverage have the potential to overcome the inconsistencies and inaccuracies inherent in relying solely on human judgment. Because of these advantages, machine vision systems for evaluating food quality and appearance, including blemish detection and sensory evaluation, have made recent advances (Du and Sun, 2004). Such objective measures, however, must be conducted so as to fully account for sensitivities of human judgment if they are to be meaningful and reliable. Several studies directed toward quantifying apple color have been published (Crassweller et al., 1984; Fan and Mattheis, 1998; Nakano, 1997; Telias et al., 2008). To date, however, no methods for quantifying apple blush extent using computer-assisted image analysis have been published, and blush quality of 'Honeycrisp' remains technically undefined.

Spectral reflectance values of the apple peel relate to apple appearance and have become useful as non-destructive surrogates for chemical analysis (Merzlyak, 2006; Merzlyak et al., 2003). Merzlyak et al. (2003) showed a strong correlation $\left(R^{2}=0.93\right)$ between anthocyanin content in fruit skin and the AI.

$$
\mathrm{AI}=\mathrm{R}_{800} / \mathrm{R}_{550}-\mathrm{R}_{800} / \mathrm{R}_{700}
$$

where $\mathrm{R}_{800}, \mathrm{R}_{550}$, and $\mathrm{R}_{700}$ are percent reflectance from the apple surface at 800-, 550-, and 700-nm wavelengths, respectively, of the electromagnetic spectrum of a pulsed xenon bulb. Anthocyanins are important to considerations of apple appearance because they are the primary pigment responsible for blush in apple (Saure, 1990).

The objectives of this study were to: 1) define categories of blush coverage intensity and evaluate blush coverage extent in the apple cultivar Honeycrisp; 2) compare measurement of apple blush intensity among a) a $\mathrm{AI}_{\mathrm{m}}$ calculated from spectral measurements, b) $\mathrm{CO}$, and c) human judgment; 3) assess the efficacy of DIA of color-calibrated digital photography as a tool to measure blush coverage extent; and 4) to determine the differences between human judgment and DIA for evaluation of blush coverage extent.

\section{Materials and Methods}

Apples were collected at harvest in 2009 and 2010 from a trial of 10 experimental 'Honeycrisp' strains at the Fruit Research Extension Center of Pennsylvania State University and analyzed for blush quality. Four replicates of 20 fruit were collected at harvest in each year from four-tree experimental units. Because the trial of experimental cultivars consists of a wide range of pigmentation tendencies (in 2009, CIELAB $\mathrm{h}_{\mathrm{ab}}$ values ranged from 102.1 to 19.5 ; in 2010, CIELAB $\mathrm{h}_{\mathrm{ab}}$ values ranged from 100.2 to 20.7), a large amount of color variability was available for each year of the study. Evaluation of the intensity of blush of the 'Honeycrisp' strains was conducted through direct human perception, colorimetry with a Konica Minolta CM2600D benchtop spectrophotometer (Konica Minolta Sensing Inc., Osaka, Japan), spectral analysis of portions of the reflected electromagnetic spectrum with the Konica Minolta CM-2600D, and image analysis applied to colorimetrically corrected photographs from a Panasonic Lumix DMC-G2 digital camera (Panasonic Corporation, Osaka, Japan). Blush coverage extent was analyzed with human perception and digital image analysis in both years of the study.

Human perception of apple blush quality was conducted to define the color and spectral 
characteristics of five grades of 'Honeycrisp' blush. The five grades of blush were defined as: 1) "non-blush," 2) "slight blush, not marketable," 3) "minimum marketable blush," 4) "clearly marketable blush," and 5) "outstanding marketable blush." One hundred fifty uniform color patches, $1 \mathrm{~cm}$ in diameter, were selected and circled with permanent marker on the apples collected in 2010 to represent a wide range of color found in 'Honeycrisp'. Care was taken to avoid areas of striping that contain color complexity so as to minimize variance and maximize color uniformity. Four experienced, non-colorblind observers from the apple industry were asked to categorize each apple blush patch into one of the five grades of blush. The observers were from the Mid-Atlantic and Midwest regions of the United States. As a result of the high level of agreement on blush quality among the observers, we determined that more observers would not be necessary. Each color patch was then analyzed with colorimetry, spectrophotometry, and image analysis of digital photography. Our analyses indicate the extent to which each blush category is a coherent class with definable boundaries and which methods are sensitive and consistent enough to provide reliable quantitative definitions of these classes.

Human judgment of apple blush coverage extent was then conducted on 110 colorimetrically calibrated images of 'Honeycrisp' fruits from the 2009 growing season. Ten images from each of 11 blush values calculated with digital image analysis were included representing $0 \%, 10 \%, 20 \%, 30 \%$, $40 \%, 50 \%, 60 \%, 70 \%, 80 \%, 90 \%$, and $100 \%$ blush. The images were displayed in random sequential order on a color-calibrated computer monitor and seven experienced observers were asked to rate the extent of blush coverage visible in the images from $0 \%$ to $100 \%$ blush. They were told only to rate 110 images for blush coverage extent (\%) and not given any other information. Image analysis techniques were performed on each image to give pixel-by-pixel counts of blush and non-blush portions of each apple. Human judgment and image analysis output were then compared statistically using linear regression. Because no experiment on the similarity between apple blush judged by observations of full apples and single images of partial apples judged with digital image analysis was performed, conclusions about the comprehensibility of digital image analysis for characterizing blush on the full skin of the apple were not made. We intended only to show the relationship between human perception of blush in a single perception moment and digital image analysis of a single scene of identical composition. It was important that we standardize the presentation of blush coverage to make sure multiple observers were seeing the same scene. Presenting viewers with images of real apples served this purpose. The limitations of this approach are that we cannot make conclusions about the similarity between digital image analysis of flat images and three-dimensional perception of curved apples that can be turned in the hand of the observer.

For the image analysis portion of this study, we created simple macroscripts for analyzing digital photographs, scripts that could be implemented by a broad spectrum of users within the widely available opensource Java-based computer program, Image J (National Institutes of Health, 2010). These macros process colorimetrically corrected images of apples within a given directory in two ways. The first macro modifies each image by eliminating the background color from the image and setting its value to null. The next macro quantifies pixels in the image into two categories: pixels displaying apple blush and pixels displaying apple nonblush using the boundary between blush and non-blush that corresponds to CIELAB $\mathrm{h}_{\mathrm{ab}}=$ 46.5 (see "Results") and gives summary statistics of percent of the apple covered in blush. The macros are automated to allow large volumes of data to be processed quickly and efficiently. They can also be easily modified to answer other questions about apple appearance such as blemish occurrence and apple size and shape. The authors have made the macros available to the general public on their web site (<http://frec.cas.psu.edu/ appleImageAnalysis.html $>$ ).

Colorimetry was performed with the CM2600D spectrophotometer in CIE $L^{*} C^{*}{ }_{a b} h_{a b}$ color space of International Commission on Illumination on the $1501-\mathrm{cm}$ uniform apple color patches, where $\mathrm{L}^{*}$ represents the lightness of the color, $\mathrm{C}_{\mathrm{ab}}$ * represents chroma, or saturation intensity, and $\mathrm{h}_{\mathrm{ab}}$ represents hue, or the angular component of the polar representation of CIELAB color space (CIE, 1978). The reference illuminant was D65 and the observer angle was set to $2^{\circ}$.

Spectral analysis was performed with output from the CM-2600D at 10-nm increments from 360 to $740 \mathrm{~nm}$. Percent reflectance of a pulsed xenon bulb from the sample was measured at each $10-\mathrm{nm}$ increment of the electromagnetic spectrum on the $1501-\mathrm{cm}$ uniform apple color patches. A modified index $\mathrm{AI}_{\mathrm{m}}$ was calculated for each sample after Merzlyak et al. (2003).

$$
\mathrm{AI}_{\mathrm{m}}=\mathrm{R}_{740} / \mathrm{R}_{550}-\mathrm{R}_{740} / \mathrm{R}_{700}
$$

In our modification of the $\mathrm{AI}, \mathrm{R}_{740}$ was substituted for reflectance at $\mathrm{R}_{800}$ used by Merzlyak et al. (2003). This was necessary because the highest reading from the CM$2600 \mathrm{D}$ is $\mathrm{R}_{740}$. Most benchtop spectrophotometers do not give readings far beyond the visible range of light, considered to be 750 $\mathrm{nm}$ for most people. Reflectance at the 800$\mathrm{nm}$ wavelength is beyond the upper limits that the human eye can detect and beyond the capabilities of almost all widely used benchtop spectrophotometers. The effects of the modification of the index is expected to be minimal because reflectance for all apple samples begins to converge strongly after $\sim R_{730}$ (Fig. 1; see also Fig. 2B in Merzlyak et al., 2003). In addition, because we are mostly interested in relating instrumentation to human perception of apple blush, we chose to stay within the visible range of the electromagnetic spectrum. We adopt the $\mathrm{AI}_{\mathrm{m}}$ index here because of its use and its strong relation to human perception of blush, not as a way of estimating anthocyanin content per se. Further study is needed to directly relate $\mathrm{AI}_{\mathrm{m}}$ to anthocyanin content in 'Honeycrisp'.

In general, consumer cameras are not scientific instruments capable of giving precise color information because data from cameras are not recorded as objective measurements directly commensurate to other cameras. Also, inaccuracies of color represented through camera processes are inevitable as a result of fundamental differences between the ways cameras process electromagnetic information and the processing sensitivities of the human eye. Nevertheless,

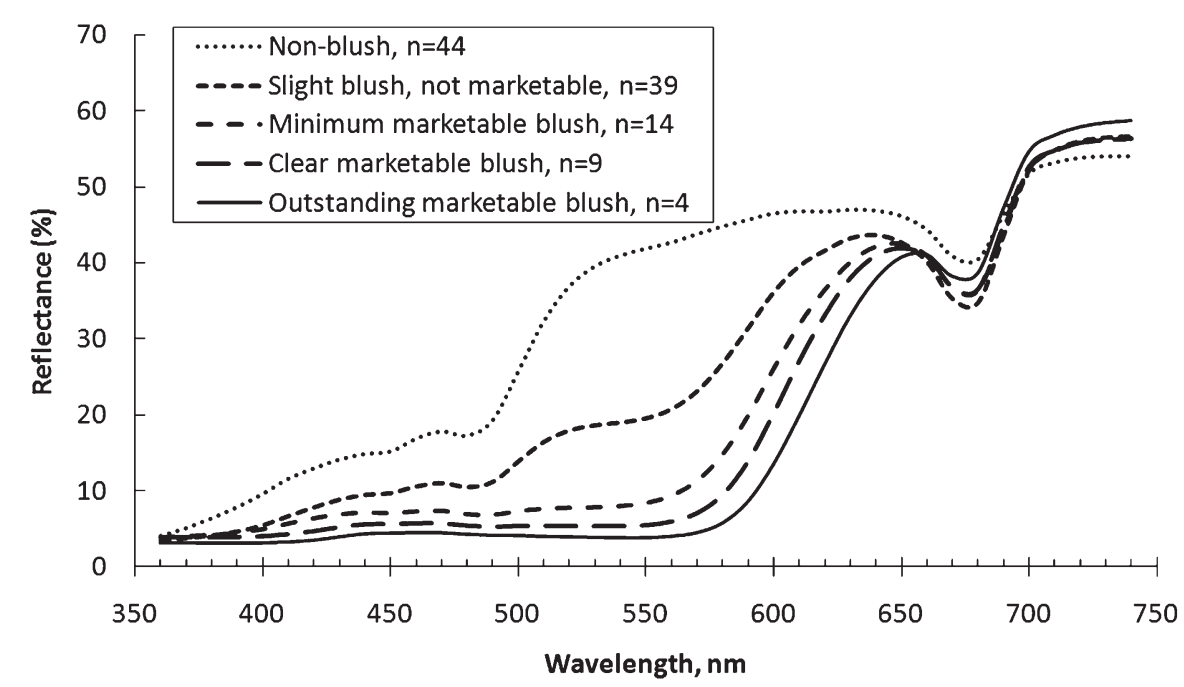

Fig. 1. Average spectral response for 'Honeycrisp' apple color patch samples as categorized by observers. Only patches with unanimous classifications among observers were included in the averages. The solid and broken lines indicate percentage reflectance at different wavelengths of reflected light for the four blush classes indicated in the legend. 
cameras offer versatility, intuitive output, immediacy, and the opportunity for automated pattern recognition that can save time and effort while increasing analytical consistency (Du and Sun, 2004). We used a Panasonic Lumix DMC-G2 digital camera to photograph apples that were placed in a light box constructed from poster board. The light box was built to provide adequate shading from outside light sources while maximizing controlled illumination similar to the one described by Nakano (1997). Light sources in the interior of the light box consisted of two Phillips halogen 75-W PAR wide flood lights, 1050 Lumens each, mounted to give reflected light from two uniform white surfaces to the sides and front of the mounted apples. Translucent diffusion paper was mounted between the translucent glass apple pedestal and the light sources to promote even illumination and reduce glare on the surface of the apples. Uniform camera settings and light conditions were maintained for all photographs. Camera white balance was adjusted with a reference white color chip placed in the light box on the pedestal used for mounting apples. Aperture, shutter speed, ISO exposure index, focal distance, and exposure time were kept constant for all samples and standards. Images were captured in photographic industry standard RAW format. A circular polarizing lens was used to further minimize glare. Background color behind the apple pedestal consisted of a shade of blue not found in apple skin to facilitate easy post-processing of apple images and removal of non-apple pixels from each image. All efforts were made to eliminate device-dependent variation between images.

A method for converting device-dependent RGB color camera output into approximate device-independent measurements in CIE $L^{*} \mathrm{C}_{\mathrm{ab}} * \mathrm{~h}_{\mathrm{ab}}$ color space is possible within limited expectations of accuracy, although each camera must be calibrated individually through an extensive calibration or profiling process (León et al., 2006). Commercial software is available for such calibrations. We used the X-Rite ColorChecker Passport System (X-Rite, 2010) for calibration of our camera output for convenience and to assess whether a widely available camera calibration product could result in camera color accuracy sufficient for basic apple blush analysis. The X-Rite ColorChecker consists of reference standard color targets (Munsell, 2007) and software that creates a camera profile that modifies camera output to most closely approximate the color values of the reference standard color targets. The camera profile can be stored and then applied to other camera output such as images of samples for measurement. Camera output was calibrated according to the profile and output was expressed in terms of hue values approximating CIE L* $\mathrm{C}_{\mathrm{ab}} * \mathrm{~h}_{\mathrm{ab}}$ color space. Our goal was to assess the viability of color and blush coverage extent analysis using a typical consumer camera and to determine whether accuracy, precision, and sensitivity of camera output could be made sufficient enough through color calibration to answer basic questions about 'Honeycrisp' apple blush.

Statistical analysis consisted of analysis of variance with the Tukey-Kramer method for multiple comparisons to provide means separation between measurements of categories of blush as determined by observers and the application of Cohen's kappa coefficient for determining the degree of interrater agreement between qualitative determinations of blush. Cohen's kappa is given as $K=\frac{\operatorname{Pr}(a)-\operatorname{Pr}(e)}{1-\operatorname{Pr}(e)}$, where $\operatorname{Pr}(\mathrm{a})$ is the agreement among raters and $\operatorname{Pr}(\mathrm{e})$ is the probability of chance agreement assuming random selection (Cohen, 1968). Because it includes the probability of agreement occurring by chance, it is considered more robust than simple percent agreement.

\section{Results and Discussion}

Spectral reflectance from the apple color patches ranged most widely in the 500- to $550-\mathrm{nm}$ region of the spectrum, tended to converge strongly above $700 \mathrm{~nm}$, and flatten near the 740-nm region (Fig. 1). Merzlyak et al. (2003) reported strong relationships between anthocyanin pigments in apple peel and the spectral reflectance at 550- and 700-nm wavelengths. Spectral signatures of average values for the reflectance of color disks in the five blush categories appeared to be sufficiently different to facilitate quantitative analysis (Fig. 1).

Quantification of the boundaries between blush and non-blush as determined by the inspectors was possible for all analytical methods. Colorimetric analysis of the apple color patches most closely matched the determination of blush intensity by human judgment, although all methods yielded high Cohen's kappa values (Table 1). The strongest relationships were between blush intensity determined by image analysis and blush by spectral analysis (kappa $=0.99$ ) with only one instance of disagreement.

The five blush quality categories were most strongly differentiated with colorimetry and spectrophotometry (Table 2). Both methods resulted in complete statistical mean separation between all categories of blush. Spectral analysis with the $\mathrm{AI}_{\mathrm{m}}$ had the advantage that it provided greater conciseness, offering complete separation between blush categories with only one value. Photographic image analysis resulted in statistical

Table 1. Matching matrix. ${ }^{2}$

\begin{tabular}{|c|c|c|c|c|c|}
\hline & \multicolumn{2}{|c|}{ Human judgment } & \multirow[b]{2}{*}{ Total } & \multirow[b]{2}{*}{ Agreement (\%) } & \multirow[b]{2}{*}{ Cohen's kappa } \\
\hline & Blush & Non-blush & & & \\
\hline \multicolumn{6}{|c|}{ Spectral analysis $\left(\mathrm{AI}_{\mathrm{m}}\right)$} \\
\hline Blush & 209 & 19 & 228 & 92 & \multirow[t]{2}{*}{0.897} \\
\hline Non-blush & 10 & 362 & 372 & 97 & \\
\hline \multicolumn{6}{|c|}{ Colorimetry (CIELAB $\left.h_{a b}\right)$} \\
\hline Blush & 201 & 18 & 228 & 92 & \multirow[t]{2}{*}{0.904} \\
\hline Non-blush & 9 & 366 & 372 & 98 & \\
\hline \multicolumn{6}{|c|}{ Image analysis (hue) } \\
\hline Blush & 208 & 16 & 224 & 93 & \multirow[t]{2}{*}{0.903} \\
\hline \multirow[t]{3}{*}{ Non-blush } & 11 & 365 & 376 & 97 & \\
\hline & \multicolumn{2}{|c|}{ Image analysis (hue) } & \multirow[b]{2}{*}{ Total } & \multirow[b]{2}{*}{ Agreement (\%) } & \multirow[b]{2}{*}{ Cohen's kappa } \\
\hline & Blush & Non-blush & & & \\
\hline \multicolumn{6}{|c|}{ Spectral analysis $\left(\mathrm{AI}_{\mathrm{m}}\right)$} \\
\hline Blush & 56 & 1 & 57 & 98 & \multirow[t]{2}{*}{0.99} \\
\hline Non-blush & 0 & 93 & 93 & 100 & \\
\hline \multicolumn{6}{|c|}{ Colorimetry (CIELAB $\left.h_{a b}\right)$} \\
\hline Blush & 56 & 2 & 58 & 97 & \multirow[t]{2}{*}{0.97} \\
\hline \multirow[t]{3}{*}{ Non-blush } & 0 & 92 & 92 & 100 & \\
\hline & \multicolumn{2}{|c|}{ Spectral analysis $\left(\mathrm{AI}_{\mathrm{m}}\right)$} & \multirow[b]{2}{*}{ Total } & \multirow[b]{2}{*}{ Agreement (\%) } & \multirow[b]{2}{*}{ Cohen's kappa } \\
\hline & Blush & Non-blush & & & \\
\hline \multicolumn{6}{|c|}{ Colorimetry (CIELAB $\mathrm{h}_{\mathrm{a}}$ ) } \\
\hline Blush & 53 & 0 & 53 & 100 & 0.96 \\
\hline Non-blush & 3 & 94 & 97 & 97 & \\
\hline
\end{tabular}

${ }^{2} \mathrm{AI}_{\mathrm{m}}$ blush was defined as the spectral reflectance of values of the modified Merzlyak anthocyanin index $\left(\mathrm{AI}_{\mathrm{m}}\right)$ greater than 4.3 .

Table 2. Empirical definitions of blush categories for 'Honeycrisp' apple.

\begin{tabular}{|c|c|c|c|c|c|c|}
\hline \multirow[b]{2}{*}{ Observer blush category } & \multirow[b]{2}{*}{ No. } & \multicolumn{3}{|c|}{ Colorimetric } & \multirow{2}{*}{$\begin{array}{c}\text { Spectral } \\
\mathrm{AI}_{\mathrm{m}}\end{array}$} & \multirow{2}{*}{$\begin{array}{c}\text { Photographic } \\
\text { image analysis } \\
\left(\mathrm{h}^{\circ}\right)\end{array}$} \\
\hline & & $\mathrm{L}^{*}$ & $\mathrm{C}_{\mathrm{ab}} *$ & $\mathrm{~h}_{\mathrm{ab}}$ & & \\
\hline "No blush" & 48 & $68.0 \mathrm{a}$ & $37.4 \mathrm{~b}$ & $87.5 \mathrm{a}$ & $0.31 \mathrm{e}$ & $86.5 \mathrm{a}$ \\
\hline "Slight blush, not marketable" & 47 & $55.1 \mathrm{~b}$ & $35.8 \mathrm{c}$ & $59.1 \mathrm{~b}$ & $2.14 \mathrm{~d}$ & $60.5 \mathrm{~b}$ \\
\hline "Minimum marketable blush" & 30 & $42.7 \mathrm{c}$ & $38.8 \mathrm{a}$ & $32.6 \mathrm{c}$ & $6.88 \mathrm{c}$ & $34.1 \mathrm{c}$ \\
\hline "Clearly marketable blush" & 19 & $39.2 \mathrm{~d}$ & $39.4 \mathrm{a}$ & $28.2 \mathrm{~d}$ & $9.30 \mathrm{~b}$ & $28.8 \mathrm{~d}$ \\
\hline "Outstanding marketable blush" & 6 & $34.3 \mathrm{e}$ & $39.6 \mathrm{a}$ & $25.6 \mathrm{~d}$ & $14.15 \mathrm{a}$ & $26.3 \mathrm{~d}$ \\
\hline $\begin{array}{l}\text { Overall significance (Tukey's error } \\
\text { rate } \alpha<0.05 \text { ) }\end{array}$ & & $* * *$ & $* * *$ & $* * *$ & $* * *$ & *** \\
\hline
\end{tabular}

*** indicates significance at $\alpha<0.001$. 

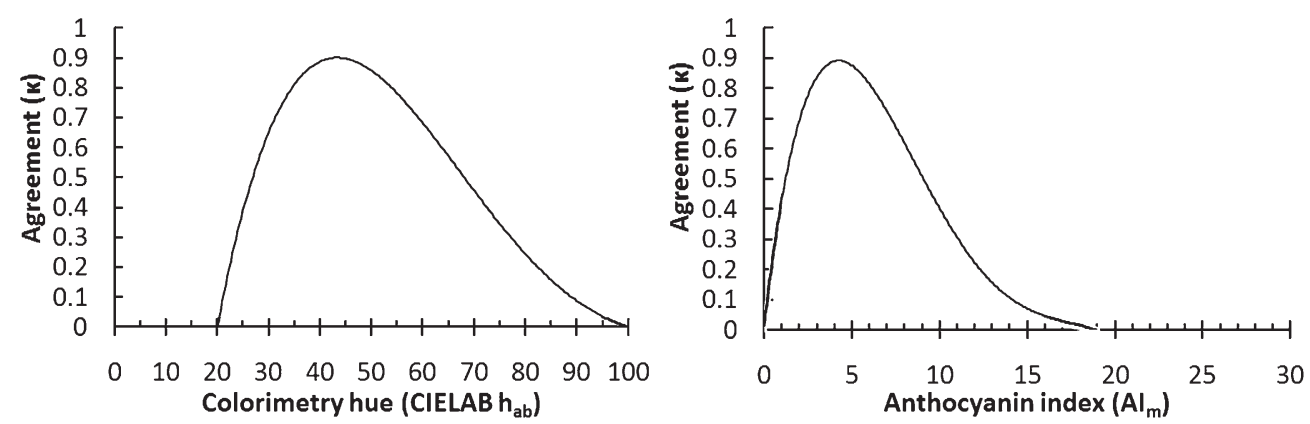

Fig. 2. Cohen's kappa agreement between human judgment of blush/non-blush classification and the instrumented blush/non-blush intensity threshold given on the $\mathrm{x}$ axis. High values of agreement indicate threshold values that best approximate human judgment of the boundary between blush and non-blush.

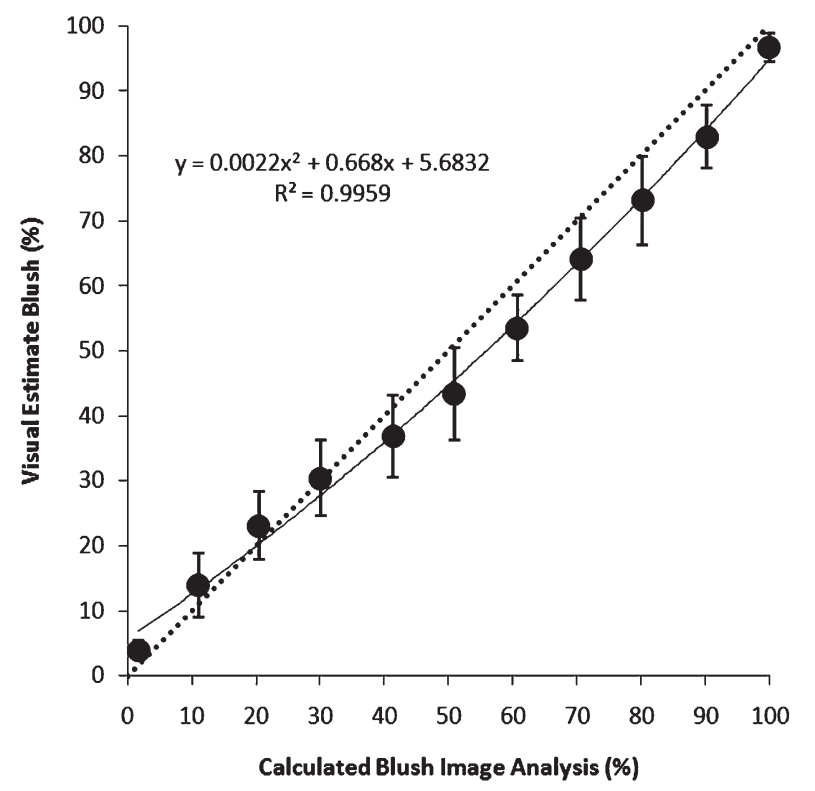

Fig. 3. Apple blush coverage estimates by observers and through automated image analysis of digital images with ImageJ software. Error bars represent $1 \mathrm{sE}$ for the visual estimate at the given blush level. $\mathrm{N}=110$.

means separation between all categories except between "clearly marketable blush" and "outstanding marketable blush," which were statistically indistinguishable in photographic analysis. For distinguishing between categories of blush, either spectral analysis or colorimetry is most appropriate, whereas image analysis is less sensitive to the slight differences between clear blush and outstanding blush.

Blush in 'Honeycrisp' can be defined as colorimetric values within CIE $\mathrm{L} * \mathrm{C}_{\mathrm{ab}} * \mathrm{~h}_{\mathrm{ab}}$ with $L^{*}$ values less than $49.0 \pm 3.1$ and $h_{a b}$ less than $46.5 \pm 6.4$ (chroma $\mathrm{C}_{\mathrm{ab}}$ * values were not linear with respect to increasing intensities of blush); and spectral $\mathrm{AI}_{\mathrm{m}}$ values greater than $4.3 \pm 1.3$. Deviations from these values led to decreased agreement between human observers and instrumentation-based determinations of the blush/non-blush distinction (Fig. 2). Blush can be defined for photographic images of 'Honeycrisp' apples using the previously mentioned colorimetry values, but only after device-dependent images have been calibrated using reference standard color chips and color correction techniques, preferably crossreferenced with a colorimeter or spectrophotometer.

Values of blush coverage extent as judged by trained observers and by digital image analysis were strongly associated $(P<0.001$, $R^{2}=0.99$; Fig. 3). Human observers tended to slightly overestimate coverage extent of blush in apples with low coverage of blush and underestimate coverage extent of blush in apples with high coverage of blush. This finding for human perception of 'Honeycrisp' blush is not surprising considering the experience in other fields in which observers are asked to judge coverage of contrasting features on a surface. In plant pathology studies, for example, the Horsfall-Barratt logarithmic scale for estimating percentage of leaf area covered by disease has long been used (Horsfall and Barratt, 1945). The scale was developed in response to the observation that visual acuity is proportional to the logarithm of the intensity of a stimulus (Hebert, 1982). With respect to apple blush coverage extent, presumably, observers recognize changes in blush in a non-linear fashion such that increases in blush coverage extent in apples with little blush are noticed disproportionately to increases in blush in apples with greater coverage extent of blush. More study on this phenomenon may be useful.

\section{Conclusions}

Apple blush for 'Honeycrisp' can be defined and quantified in a number of ways. Direct spectral analysis has been useful for analyzing specific chemical components in apple skin such as anthocyanins in other studies (Merzlyak, 2006; Merzlyak et al., 2003). Merzlyak's anthocyanin index, modified slightly to meet the capabilities of most benchtop spectrophotometers, relates well to the human perception of apple blush, including offering complete statistical separation of five levels of blush quality. Colorimetry, possibly the most conventional approach to the study of apple blush intensity, is likewise able to quantify differences in five levels of blush by human observers. Image analysis of digital photography, if used carefully, can offer some instrumental sensitivity toward an understanding of apple blush. The limitations in sensitivity and accuracy of image analysis recommend against its use as a substitute for colorimetry, but image analysis can give meaningful, if not precise, color information. Image analysis can provide broad capabilities in pattern recognition and quantification that conventional colorimetry and spectrophotometry cannot. We see wide potential for use of calibrated photographic output in the analysis of color patterns in 'Honeycrisp' apples in which simple classifications are needed. Digital image analysis can successfully provide efficient automated analysis of quantities of blush on the surface of 'Honeycrisp' apples where the distinction between blush and non-blush is well defined.

\section{Literature Cited}

C.I.E. 1978. Recommendations on uniform color spaces, color difference equations, and metric color terms. Suppl. No. 2 to Pub. No. 15, Paris, France.

Cohen, J. 1968. Weighted kappa: Nominal scale agreement with provision for scaled disagreement or partial credit. Psychol. Bull. 70:213-220.

Cliff, M., K. Sanford, W. Wismer, and C. Hampson. 2002. Use of digital images for evaluation of factors responsible for visual preference of apples by consumers. HortScience 37:1127-1131. 
Crassweller, R.M., J. Walker, and R.L. Shewfelt. 1984. Color evaluation of seventeen strains of 'Delicious'. Fruit Var. J. 39:21-24.

Du, C.J. and D.W. Sun. 2004. Recent developments in the applications of image processing techniques for food quality evaluation. Food Sci. \& Technol. 15:230-249.

Fan, X. and J.P. Mattheis. 1998. Bagging 'Fuji' apples during fruit development affects color development and storage quality. HortScience 33:1235-1238.

Hebert, T.T. 1982. The rationale for the HorsfallBarratt plant disease assessment scale. Amer. Phytopathol. Soc. 72:1269.

Horsfall, J.G. and R.W. Barratt. 1945. An improved grading system for measuring plant diseases. Phytopathology 35:655.

Karst, T. 2010. 'Honeycrisp' comes up big in Washington. The Packer. 10 Dec. 2010. <http://
thepacker.com/Honeycrisp-comes-up-big-inWashington/Article.aspx?oid=1253927\&aid= $117 \&$ fid=PACKER-SPECIAL-SECTIONS $>$.

León, K., D. Mery, F. Pedreschi, and J. León. 2006. Color measurement in $L^{*} a^{*} b^{*}$ units from RGB digital images. Food Res. Intl. 39:1084-1091.

Merzlyak, M.N. 2006. Modeling pigment contributions to spectral reflection of apple fruit Photochem. Photobiol. Sci. 5:748-754.

Merzlyak, M.N., A.E. Solovchenko, and A.A. Gitelson. 2003. Reflectance spectral features and non-destructive estimation of chlorophyll, carotenoid and anthocyanin content in apple fruit. Postharvest Biol. Technol. 27:197-211.

Munsell. 2007. ColorChecker rendition chart. X-Rite, Grand Rapids, MI.

Nakano, K. 1997. Application of neural networks to the color grading of apples. Comput. Electron. Agr. 18:105-116.
National Institutes of Health. 2010. ImageJImage analysis and processing in Java. Jan. 2010. <http://rsbweb.nih.gov/ij/>.

Saure, M. 1990. External control of anthocyanin formation in apple. Sci. Hort. 42:181-218.

Telias, A., E. Hoover, and D. Rother. 2008. Plant and environmental factors influencing the pattern of pigment accumulation in 'Honeycrisp' apple peels using a novel color analyzer software tool. HortScience 43:14411445.

USDA. 2002a. United States standards for grades of apples. 9 June 2010. <http://www.ams. usda.gov/AMSv1.0/getfile? $\mathrm{dDocName}=$ STELPRDC5050339>.

USDA. 2002b. Official visual aids for apples (APCC-1 A through E). Washington, DC.

X-Rite. 2010. ColorChecker Passport [software]. 19 Jan. 2011. <http://xritephoto.com>. 